\title{
Trajetória do Movimento de Libertação Nacional - Tupamaros -, 1962-1973: algumas questões de identidade e poder
}

JOSÉ PEDRO CABRERA CABRAL*

\begin{abstract}
Resumo: O presente artigo discute a trajetória do Movimento de Libertação Nacional Tupamaros - a partir de sua gestação, em 1962, até a sua derrota político-militar, em 1973. O objetivo central foca o desenvolvimento do movimento e a construção de diversas identidades, existentes em sua direção interna, que entraram em conflito pelo exercício do poder dentro da organização.
\end{abstract}

Abstract: The present article argues the trajectory of the Movimento de Libertação Nacional - Tupamaros - from its gestation, in 1962, until its political-military defeat, in 1973. The central objective focuses the development of the movement, and the construction of diverse identities in its internal direction, which lead to conflicts in the organization.

Palavras-chave: Identidade. Poder. Tupamaros.

Key words: Identity. Power. Tupamaros.

\section{Antecedentes do Movimento de Libertação Nacional - Tupamaros}

O nascimento do MLN pode ser explicado, seguramente, por motivos endógenos e exógenos, alguns de caráter sócio-econômico específico do país e outros mais conectados com a Guerra Fria e a onda de luta armada surgida com o triunfo da Revolução Cubana. Influíram outros fatores, mas a Revolução Cubana exerceu um peso fundamental na aparição do MLN, mais que as causas puramente locais. Um tema de polêmica inicial refere-se ao surgimento do movimento como "socialista" desde seus primórdios, ou

Doutor em História, professor na Universidade do Oeste de Santa Catarina - Unoesc. O presente trabalho foi realizado com apoio do CNPq.

E.mail: cabrera@unoescxxe.edu.br

Estudos Ibero-Americanos. PUCRS, v. XXXIII, n. 2, p. 156-171, dezembro 2007 
um grupo de autodefesa que, posteriormente, evoluiu para essa corrente ideológica. Variadas são as contradições nesse sentido, mas tomamos por possível a versão de seu início como grupo de autodefesa, vistas as características que o coordinador possuía e as manifestações de seus principais líderes.

José Mujica referiu-se ao nascimento do MLN como uma reunião de militantes e pequenos grupos de esquerda que se preparavam para a autodefesa diante de pretensos ataques fascistas e golpistas. Mujica afirmou que, no seu início, os Tupamaros "não tinham uma intenção ofensiva determinada pela tomada do poder, senão que se tratava de uma atitude defensiva"; 1 posteriormente, Fernandes Huidobro confirma essa versão, relatando, na sua obra Historia de los Tupamaros, as origens do movimento revolucionário liderado por Raúl Sendic, estreitamente vinculado à experiência da Revolução Cubana e às lutas dos trabalhadores açucareiros de Artigas, agrupados na Unión de Trabajadores Azucareros de Artigas UTAA. ${ }^{2}$ Segundo esse trabalho, os anos de 1962 e 1963 são importantes na conformação do núcleo inicial, constituído a partir de militantes procedentes de distintos grupos e/ou partidos de esquerda. Huidobro afirma que uma das características apontadas pelos críticos em relação ao surgimento do MLN é a de que o mesmo nasceu rompendo com a esquerda e foi se transformando numa expressão política dessa ruptura. "Formamos parte da esquerda uruguaia e compartilhávamos seus acertos e seus erros. $\mathrm{O}$ que corresponde afirmar é que rompemos com certos vícios arraigados em alguma parte dessa esquerda [...], a esquerda tradicional rompeu conosco, tomou a iniciativa". ${ }^{3}$ Na realidade, as relações entre o resto da esquerda e a nascente organização foram mais complexas, ambíguas e mutantes, de ambas as partes. Mas o intuito deste trabalho é outro: procura-se examinar o processo que incorporou o plano de ação popular, a luta armada, ao complexo curso das contradições acontecidas no país ante o acirramento autoritário e conservador.

Em 1962, formou-se o embrião organizacional que deu lugar ao surgimento do MLN. De distintos grupos e partidos de esquerda - não comunista -, os integrantes da nascente organização conhecida como El Coordinador somaram a participação de socialistas, anarquistas, integrantes do Movimiento Izquierda Revolucionário

LESSA, Afonso. La Revolución Imposible. Montevideo: Fin de Siglo, 2003, p. 73.

Sindicato dos Trabalhadores da Cana de Açúcar.

HUIDOBRO, Eleutério Fernández. Historia de los Tupamaros. Montevideo: TAE, 1989 (vol. 1), p. 45 
- MIR e do Movimiento Revolucionário Oriental - MRO. Como objetivo básico, a organização apresentou a necessidade de cumprir funções de defesa do movimento popular contra a repressão policial e os grupos fascistas, muito ativos no Uruguai desde o início de 1960. Também figurava nos seus objetivos um trabalho que visava a impulsionar e oferecer apoio a setores combativos na luta de massas, mediante enfrentamentos radicais, iniciando, assim, a transitar o caminho da luta armada com objetivos revolucionários, mas sem se propor a desenvolvê-la no imediato.

O Coordinador captou, desde seu primeiro momento, os grupos mais radicalizados da esquerda, políticos, sindicais, estudantis, já organizados em funções de autodefesa. Esses grupos possuíam algumas características particulares: pouco hierarquizados, flexíveis no organizativo e nas suas formas de mobilização. Foi importante a participação de militantes que saíram do MIR e do MRO, e que, posteriormente, fundaram o Movimento de Apoio Campesino - MAC. A presença de anarquistas no Coordinador provinha de integrantes da Federação Anarquista do Uruguai FAU, e da Agrupação Libertária Uruguaia - ALU (dissidente da FAU, em 1964). Esses grupos anarquistas, conjuntamente com outros de menor expressão (uma agrupação de independentes e a agrupação Voluntad), formaram o Movimento de Ação Revolucionária - MAR, que, em 1965, protagonizou vários atentados com explosivos. A esses grupos somou-se um contingente de trabalhadores rurais, aglutinados por Raúl Sendic na sua experiência de sindicalização e luta entre os trabalhadores da cana de açúcar e os arrozeiros, de Treinta y Tres, Paysandú e Bella Unión ${ }^{4}$.

No ano de 1963, o Coordinador realizou várias ações audazes: o roubo de armas do Tiro Suizo e da alfândega de Bella Unión, ${ }^{5}$ libertação de presos detidos num posto policial em "Uruguaiana", uma operação de expropriação e distribuição de mantimentos comestíveis numa favela de Montevidéu, apoio à segunda marcha Cañera de 1964, atentados contra empresas multinacionais e resi-

4 ALDRIGHI, Clara. La Izquierda Armada: ideología, ética e identidad en le MLN Tupamaros. Montevideo: Trilce, 2001, p. 73.

5 No ano de 1963, o Coordinador iniciou uma série de operações menores que serviram como exercício do futuro MLN. O Tiro Suizo era um clube de tiro do qual foram roubados vários fuzis praticamente sem utilidade, mas que politicamente repercutiu no cenário nacional, visto que levou à clandestinidade vários militantes da incipiente organização. As ações de Bella Unión e de Azucar foram mais eficazes em termos gerais, mas com pouco significado político. A alfândega de Bella Unión está localizada na fronteira-norte com o Brasil, e o roubo de explosivos de Pan de Azucar - cidade localizada a $120 \mathrm{~km}$ da Capital - foi de pouca significação quanto à quantidade de explosivos adquiridos. 
dências de conselheiros do governo, por motivo da ruptura das relações com Cuba, roubo de explosivos em Pan de Azucar, em 1964, e de uma loja de armas, em $1965 .{ }^{6}$

Paulatinamente, os grupos que integravam o Coordinador foram adquirindo uma gradual autonomia perante suas organizações de origem, a ponto de que logo deixaram de controlar as ações por eles realizadas. O caso de Raúl Sendic e de outros militantes do Partido Socialista serve como exemplo: o PS não contava com uma estrutura clandestina armada; assim, os militantes que integravam o Coordinador mantiveram uma dupla militância até o ano de 1966, quando rompem com o partido e passam "oficialmente" a integrar o nascente MLN. Sem dúvida, esse tipo de autonomia gerava inúmeros problemas para os partidos. Em 1964, ocorreu um amplo debate no Coordinador a respeito da possibilidade - proposta por Sendic - de transformar a estrutura armada em instrumento de um "cartel" de partidos e grupos, que conservariam suas autonomias e características específicas. Essa proposta foi descartada no Plenário de Parque del Plata, em maio de 1965.

Nesse encontro do Parque del Plata deu-se por finalizada a experiência do Coordinador. Segundo Aldrighi, com aproximadamente dois terços de seus integrantes (essencialmente os provenientes do PS, o MAC e o MIR, junto a vários trabalhadores de UTAA) constituiu-se o MLN como formação política autônoma. Os anarquistas da FAU - representados por Gerardo Gatti - não aderiram à proposta de criar uma nova organização revolucionária, visto que já integravam uma, da qual aceitavam seu programa e suas estratégias. Posteriormente, a FAU criou sua própria organização armada, a Organización Popular Revolucionaria 33 Orientales - OPR33.

No Plenário, aprovou-se o primeiro estatuto e se efetivou a eleição de uma direção, o Comitê Executivo, integrado por Raul Sendic, Tabaré Rivero Cedrés, Eleutério Fernandes Huidobro e um integrante do MIR. A partir desse momento, a organização passou a estruturar-se em células, dirigidas por um responsável militar e outro político. Fechou-se à admissão de grupos, e os militantes passaram a ser recrutados individualmente. Criaram-se direções intermediárias: coordenações militares e políticas. Pouco tempo depois, em janeiro de 1966, realizou-se a primeira Convenção, no balneário El Pinar, da qual os militantes do MIR retiraram-se ao ficar em minoria sua proposta: a do desenvolvimento do MLN

$6 \quad$ ALDRIGHI, op. cit., p. 73. 
como braço armado de um partido marxista-leninista (de orientação maoísta) e com o método de luta de guerrilha rural.

O MLN, como nova organização, se propôs ser um movimento revolucionário que vislumbrava objetivos políticos segundo as necessidades do país. Surgiu como movimento ilegal, subversivo da legalidade burguesa, mas também da tradição legalista da esquerda uruguaia. Independente em relação aos interesses de qualquer centro externo - do Estado ou revolucionário -, caracterizou-se pela liberdade de movimentos e de decisão, e pela sua inovadora metodologia: a ação, como máxima para o desenvolvimento da revolução - "a ação nos unifica, as palavras nos distanciam".

\section{Os componentes ideológicos no MLN}

As duas fontes ideológicas que o MLN utilizou para sua fundamentação estratégica foram a revolucionária socialista e a revolucionária liberal. Tanto a tradição uruguaia como sua característica de movimento, situou-o entre essas tendências, contraditorias em variados aspectos. Como ponto em comum, observa-se que ambas as teorias haviam promovido mudanças políticas ao longo dos últimos dois séculos, através da violência, para combater o que se entendia como opressão. A teoria revolucionária socialista, desde a Revolução Francesa de 1789, para eliminar a opressão política; a teoria revolucionária liberal para ir contra a opressão econômico-social.

A teoria revolucionária socialista propõe a modificação do Estado e do sistema sócio-econômico em favor das maiorias, já que tais interesses não se vêem garantidos pelo Estado capitalista, que só garante a proteção dos interesses da minoria beneficiada pelo capitalismo, e não os gerais dos cidadãos. Para essa teoria, a opressão do capitalismo é exercida em qualquer sistema político, inclusive no democrático liberal, que constitui uma das formas adotadas pelo capitalismo para manter a desigualdade. A opressão social e econômica, fruto de uma distribuição desigual da riqueza, entendia-se que somente poderia ser corrigida com a mudança do sistema e a instauração do socialismo.

A partir dessa perspectiva, o MLN considerava que mesmo que existisse "democracia representativa, regime 'legal' e governo eleito, o ocultar da exploração, da violência e da ditadura de classes detrás de formas legais constitucionais é uma tática que a oli- 
garquia tem utilizado há quase um século no país". ${ }^{7}$ Diferente das teorias gradualistas social-democratas, a teoria revolucionária socialista considera que o socialismo pode ser atingido unicamente através da revolução violenta, já que os grupos dominantes, políticos e econômicos que controlam o Estado utilizam todos os recursos, inclusive a força, para manter seus privilégios.

Na concepção ideológica do MLN, a teoria revolucionária socialista se conjugava, em alguns aspectos, com a revolucionária liberal. O ciclo de revoluções liberais européias do século XIX, realizadas para derrubar não só tiranias ou monarquias absolutas, mas também regimes constitucionais conservadores, foi promovido por minorias que atuavam "em nome do povo". Tratou-se de revoluções que pretenderam, e geralmente conseguiram, mediante o recurso da violência, a implantação e aprofundamento dos direitos políticos e das liberdades civis. Não só reivindicavam o respeito das normas constitucionais existentes, no caso de serem desconhecidas por um governo arbitrário, injusto ou opressor, mas também aspiravam à modificação da ordem jurídica constitucional. Tratava-se, portanto, de revoluções vinculadas ao estatismo democrático. ${ }^{8}$

Para Paul Gilbert (1997), a teoria revolucionária liberal se fundamenta na necessidade de restabelecer os direitos universais negados. "A revolução liberal parte da acusação de que o Estado renuncia à autoridade política, ou seja, seu direito à obediência por parte dos cidadãos, negando-lhes tanto os direitos fundamentais como parte do poder político". ${ }^{9}$ A imprensa de esquerda, especialmente o semanário Marcha, considerou o MLN como herdeiro da tradição revolucionária liberal da história uruguaia. Um dos textos mais significativos para a compreensão dessa visão é o editorial de Carlos Quijano, intitulado La Tierra Purpúrea, publicado no semanário Marcha por motivo da tomada de Pando e da morte de três tupamaros, em 17 de outubro de 1969.

Na busca de consenso, e também como forma de impulsionar a mobilização ativa do povo, o MLN apelava para a história nacional como fonte de legitimidade. As revoluções e guerras civis da história uruguaia fundamentavam a inspiração liberal revolucionária, como exemplo de direito à rebeldia contra a opressão. Realizaram-se alguns comparativos com fatos da história nacional,

MLN. Documento 5. Montevideo: mimeo, 1970, p. 4.

HOBSBAWN, Eric. Las Revoluciones Burguesas. Madrid: Guadarrama, 1974, p. 76.

GILBERT, Paul. Il Dilema del Terrorismo. Studio di Filosofia Política Applicata. Milano: Fertrinelli, 1997, p. 126. 
como o caso do levante de 1935, o qual, com efeito, revelava algumas semelhanças com o discurso e a política do MLN, tais como: a) o levante foi impulsionado por um conjunto de pessoas de heterogêneas origens políticas, na sua maioria liberais; b) sua bandeira foi de luta contra a opressão política; c) seus objetivos, o restabelecimento do estado de direito, da democracia liberal e das liberdades civis; e d) o método, uma conspiração que terminou em insurreição armada e foi promovida por um reduzido número de ativistas. ${ }^{10}$ Assim, as guerras civis do século XIX não eram percebidas como momentos apenas deixados para trás, mas vinculados, para muitos tupamaros, ao presente, através de vividas tradições. Simbolizavam a legitimidade do recurso das armas para defender as razões das minorias políticas contra o poder central do Estado, mas também o culto à rebeldia antiautoritária de inflexões libertárias.

Outro ponto importante sobre as referências à história nacional estava no discurso artiguista. O MLN declarava encarnar a continuidade de suas idéias. $\mathrm{O}$ discurso artiguista permitia reforçar o sentimento de Nação numa perspectiva latino-americana e encontrar um fio de continuidade entre a ação do MLN e aquela "revolução inconclusa". No ideário de Artigas, o MLN encontrava conteúdos democráticos radicais e de autogoverno, liberdades civis e propósitos de justiça social contemplados no seu avançado projeto agrário. Os valores que se associavam à sua figura, dignidade, valentia, ao seu humanismo, à sua capacidade militar e liderança popular, ocuparam lugar central na ideologia tupamara.

10 Conscientes de sua condição de minoria, ao iniciar, em janeiro de 1935, o que definiam como uma guerra civil, os insurretos não pretenderam derrotar com suas únicas forças o regime de Gabriel Terra (presidente da República de 1931-1936, colorado, frontal inimigo do batllismo e opositor do sistema colegiado de governo), senão que queriam constituir um fator detonante que despertasse a consciência de sua opressão na cidadania e promover a insurgência, que seria conduzida pelas cúpulas das frações anti-terristas dos partidos tradicionais. Os combatentes da revolução de 1935 também se definiam como guerrilheiros. Na sua marcha para Paso Morlán, ocuparam uma delegacia de polícia, desarmaram policiais e expropriaram veículos para apoiar o combate. Enfrentaram, em inferioridade de armamento, forças numerosas e bem armadas. Derrotada a revolução, pouco tempo depois, Basílio Muñoz, no Manifesto de Rio de Janeiro (julho-agosto de 1935), reivindicava, junto à luta pela liberdade política, a luta antiimperialista para conseguir a independência econômica latino-americana. A experiência conspirativa e revolucionária lhes incentivou a propor a criação de uma Frente Antifascista e Antiimperialista, a "Frente Popular" (GONZÁLEZ, Adolfo Aguirre. La Revolución de 1935. Montevideo: Librosur, 1985, p. 86-94). 


\section{O papel do Estado atribuído pelo MLN}

A partir da maior intensificação da política repressiva na década de 1960, o Estado era visto pelo MLN, e também pelo conjunto da esquerda, como um "simples comitê de assuntos da burguesia", segundo a visão marxista. Uma minoria de 600 famílias controlava a maior parte dos recursos econômicos do país: terra, indústria, finanças e comércio exterior. Essa minoria estava representada no governo pelos partidos tradicionais que, majoritariamente, possuíam uma estreita ligação com o imperialismo. Ao considerar o Estado como instrumento de domínio da oligarquia, a luta revolucionária tomava a forma de ataque ao Estado, e devia, em conseqüência, adotar formas político-militares, disputando necessariamente o poder no mesmo território que o adversário. Atacar o Estado significava atacar os indivíduos que cumpriam funções de poder em si mesmo, não só a quem combatia na sua defesa.

Para amplos setores da população, o Estado deixou de representar os interesses gerais do corpo social. Sua capacidade de mediação dos interesses conflitantes e a resolução por vias institucionais dos conflitos viram-se diminuídas ou simplesmente paralisadas. As demandas pacíficas dos trabalhadores e estudantes viam-se desatendidas, enquanto as respostas violentas do Estado às mobilizações faziam-se cada vez mais intensas. Reiteradas violações dos direitos humanos e torturas de detidos desmentiam fortemente os valores de liberdade, tolerância e humanismo que o Estado uruguaio, através de suas instituições, declarava defender. Nesse contexto, nos últimos anos da década de 1960, intensificouse a polarização entre Estado e a esquerda uruguaia, em todas suas correntes e tendências.

Em dezembro de 1967, difundiu-se o primeiro documento público firmado como MLN. Nesse documento, evidenciam-se algumas das características que marcaram o projeto do MLN e que assinalavam, entre outras: "A única via para a libertação nacional e a revolução socialista será a luta armada [...] A luta armada em nosso país é não só possível, senão que imprescindível: única forma de se fazer a revolução". ${ }^{11}$ Citando Regis Debray, o mencionado documento diz: "No Uruguai também o acento principal deve colocar-se na guerra de guerrilhas [...] $\mathrm{O}$ trabalho insurrecional é hoje o trabalho político número um [...] O decisivo

11 MLN. Documento nº 1. Montevideo: mimeo, dezembro de 1967, p. 3. 
para o futuro é a abertura de focos militares, e não políticos. Se vai de um foco militar para o movimento político". 12

Assim, desde o seu primeiro documento, o MLN definia-se pela guerra de guerrilhas como estratégia priortária, deixando o trabalho político em segundo plano. As concepções de Debray influenciaram prematuramente a incipiente organização que foi implantando, de forma gradativa, uma concepção militarista que levou o MLN a um rotundo fracasso em 1972. Desde 1967, foi notória a maior influência de Debray no MLN do que a da própria Revolução Cubana e da experiência dela extraída.

Em maio de 1968, o MLN emitiu um comunicado que reafirmou os níveis e limites nos quais se propunha desenvolver seu acionar revolucionário. Esse comunicado ficou conhecido como Documento $n^{\circ}$ 3, e se caracterizou como explicitação política e teórica de qual era a concepção estratégica foquista, tal como a desenvolvia o MLN. Na sua essência, o documento afirma:

Nossa estratégia implica a instalação da luta armada sistemática; apenas estejamos preparados para fazê-la realidade e existam condições para isso. [...]. Tal estratégia consiste esquematicamente no seguinte: um grupo armado para manter a luta prolongada, quer dizer, preparado como para não ser destruído de imediato ao iniciar as ações. Ante o fato consumado, o resto da esquerda se vê ante estas alternativas: ou somar-se à luta armada ou permanecer indiferente à mesma, ou servir de "soldado tranqüilo" da contrarevolução. [...]. Não devemos nos organizar gremial ou politicamente em forma pública, mesmo que fazer política ou gremialismo hoje seja lícito e não sancionável penalmente. No futuro não vai ser assim, e de não levá-lo em consideração estaremos facilitando o trabalho de nossos inimigos. ${ }^{13}$

No regulamento da organização estabelecia-se, no seu artigo 1ํㅜ que "o MLN aspira a ser a vanguarda organizada das classes exploradas em sua luta contra o regime; é a união voluntária e combativa de quem é consciente de seu dever histórico". Na continuidade, afirma: "Portanto, o MLN trata de guiar o povo uruguaio pelo verdadeiro caminho de sua libertação definitiva, que se concretizará na formação de uma sociedade socialista". ${ }^{14}$

O objetivo oficial do MLN era claro: a revolução mediante a luta armada como único instrumento possível. Fica explicitado o desprezo às alternativas de caráter eleitoral. Em janeiro de 1968,

12 Idem.

13 MLN. Documento $n^{\circ}$ 3. Montevideo: mimeo, maio de 1968, p. 2-5.

14 MLN. Regulamento do MLN - Exemplar sem data. In: LESSA, op. cit., p. 99. 
como resultado da Segunda Convenção Nacional, o MLN procurou realizar alguns ajustes e fez a autocrítica de alguns aspectos de sua linha militar. O Documento $\mathrm{n}^{\mathrm{o}} 2$ recolheu esses lineamentos, analisando o que denominava de el problema de la acción. Estabelecia a existência de duas deformações fundamentais, tanto na base como nos organismos de direção: uma delas foi definida como "militarismo" e consistia em colocar algumas questões técnico-militares por cima de tudo, de forma desmesurada, esquecendo, por completo, o objetivo especificamente político da luta - a preocupação de preservação desmesurada do aparelho, como se fosse um fim em si mesmo. A outra deformação assinalada se definia como izquierdismo, e consistia em acreditar que tudo radicava em espetaculares ações gloriosas; em reagir com tremendismo frente a acontecimentos políticos.

\section{$4 \quad$ A luta armada e a opção eleitoral}

Em dezembro de 1970, o MLN trouxe ao conhecimento público um documento de adesão à Frente Ampla, no qual manifesta sua descrença no processo eleitoral que se avizinhava e a crença na total inviabilidade de se chegar a um governo revolucionário através do pleito eleitoral. Apesar disso, os tupamaros manifestaram seu apoio à frente em formação, criticando, porém, o motivo pelo qual a esquerda se unificava: "o MLN entende como positivo que se forme uma união de forças populares tão importantes, mas lamenta que essa união tenha acontecido precisamente por motivo das eleições, e não anteriormente". Realizaram uma crítica no sentido da desunião tradicional da esquerda, a perda de espaço e seu conseqüente enfraquecimento para enfrentar com efetividade o autoritarismo dominante da época. "Hoje, muitas forças da esquerda e progressistas parecem haver superado estas diferenças, ou algumas delas, e se têm unido a esta frente que, mesmo que não constitua uma integração total das forças populares, ${ }^{15}$ é já uma das preocupações da reação". ${ }^{16}$

15 Na formação da Frente Ampla, não participaram a FAU, o MRO e o PRT. Com diferentes argumentos, essas organizações ficaram excluídas do processo de formação da Frente, pelo entendimento de que o processo eleitoral não conduzia à revolução. Essa discussão foi também presente internamente no MLN, onde predominou a adesão à Frente como posição oficial.

16 MLN. MLN - Tupamaros y Frente Amplio. Montevideo: Ed. MLN: Propaganda Central. 1989, p. 10-11. 
O documento finaliza com um apelo ao patriotismo e reivindicando a história nacional, onde se pode identificar a concepção nacionalista artiguista do MLN. "Os problemas do país serão solucionados quando a terra estiver a serviço da sociedade e não de um pequeno grupo de privilegiados; quando as riquezas que produza estiverem a serviço do povo, quando esteja a serviço dos mais infelizes, como o quis Artigas há 150 anos. [...]. Quando sejam rompidos os laços indignos que nos unem à exploração estrangeira e desenvolvamos uma política exterior patriótica e verdadeiramente independente". ${ }^{17}$ Acreditavam que a Frente Ampla poderia constituir uma corrente popular capaz de mobilizar importantes setores trabalhadores e estudantis por um programa nacional e popular. Concluíram o documento reafirmando a validade da luta armada: "A luta armada e clandestina dos Tupamaros não se detém".

Ainda que contradizendo formulações anteriores, o movimento considerou necessário participar de outras formas de ação, e de fato as levou a cabo, mas sempre atreladas ao serviço da luta armada. Assim, ocorreu nas organizações sociais, na mobilização popular e se constatou, desde 1971, com a fundação da Frente Ampla. O Movimiento 26 de Marzo foi o braço legal para sua participação. Apesar de os Tupamaros não haverem apresentado um candidato próprio nas eleições de 1971, a fração "Pátria Grande", na Frente Ampla, liderada pelo ex-dirigente branco Enrique Erro - o frenteamplista mais identificado com o MLN -, foi a terceira mais votada da Frente Ampla. Chegou ao Senado da República com 70.944 votos. ${ }^{18}$

Como vanguarda revolucionária, o MLN colocava-se à frente de dois desafios históricos estipulados por sua estratégia de curto e médio prazo: 1) como a organização e seu método passariam a ganhar as grandes massas; 2) como a organização e seu método passariam a uma etapa superior de guerra, a uma etapa na qual se destruísse o aparelho armado que sustentava a oligarquia. Consideravam, ainda, os desempregados que habitavam as favelas que formavam um colar ao redor de Montevidéu - e ainda formam - como o setor "potencialmente mais revolucionário", e propunham a formação de uma "Frente de Libertação Nacional", com conteúdo comum antiimperialista e antioligárquico.

Como salienta Lessa, a história imediata encarregou-se de demonstrar dois fenômenos: 1) a importância que efetivamente

17 Idem.

18 LESSA, op. cit., p. 116. 
alcançaram os aspectos levantados pelos Tupamaros para seu próprio desenvolvimento; e 2) o mais completo fracasso nesses dois objetivos. Não chegaram ao triunfo político que implicava ganhar as grandes massas, nem obtiveram o êxito militar que perseguiam. Seguramente, uma vez mais, a sobrevalorização do obtido até esse momento e, principalmente, um erro de análise da realidade constituíram esse fracasso. ${ }^{19}$

Os documentos posteriores não fizeram mais do que reafirmar a linha estratégica da luta armada, ainda que com algumas variantes determinadas, em sua maioria, pela conjuntura - em alguns casos com conteúdos de autocrítica. Ante a iminência da derrota militar (a partir de 1972), e fundamentalmente depois, quando se produziu a diáspora e o exílio, começou-se a perceber importantes modificações no pensamento tupamaro. $\mathrm{O}$ fracasso militar do MLN pareceu uma prova concreta de que a guerrilha exclusivamente urbana não poderia triunfar. E muito menos em países de tradição democrática e com índices importantes de inserção social. Tanto Guevara quanto Debray tinham advertido para a inviabilidade da luta armada no Uruguai. De fato, os únicos grupos armados triunfantes na América Latina do século XX foram rurais e tiveram como cenários países com regimes ditatoriais, exclusão política e marcada exclusão social, casos de Cuba e da Nicarágua.

\section{Conflitos de poderes no MLN: o início do fim}

Em março de 1972, o MLN celebrou uma convenção das colunas $^{20}$ do interior e de Montevidéu. Depois de um longo enfrentamento ideológico entre as duas linhas, decidiu proceder à substi

]tuição da equipe dirigente por uma nova. A decisão por coesão ideológica e a diversidade da origem dos militantes que se reuniram para fundar o MLN constituíam uma contradição latente, mas que parecia superada. Debray afirma que sem subestimar o êxito do movimento na superação de sua disparidade, num pri-

19 Ibid.

20 O MLN estava estruturado internamente a partir de células (grupos de quatro a seis integrantes) que, por sua vez, estruturavam-se em colunas (grupos integrados por quatro a seis células). As colunas tinham funções específicas dentro da organização. Elas dividiam-se em colunas: políticas, de logística, de ação direta, de infra-estrutura, entre outras. No total, estima-se que o número de colunas foi de aproximadamente 30, no seu momento de maior desenvolvimento (1971-1972). A convenção das colunas implicava uma instância de decisão democrática dentro da organização; estavam representadas pelos coordenadores de cada coluna. 
meiro momento, e a harmonização de seus componentes, torna-se obrigatório reconhecer que a solução encontrada empiricamente a esse problema foi a tal ponto "prática", ou seja, desprovida de base ideológica clara, que em grande parte voltou-se "teórica".

A unificação já havia se dado na primeira Convenção, em janeiro de 1966. Posteriormente, em março de 1968, a II Convenção aprovou formalmente o princípio de centralismo democrático como norma de organização, assim como os estatutos, com muita ênfase sobre o exercício do centralismo e a disciplina, necessários para qualquer organização com as características relativas ao exercício de uma democracia interna efetiva, como forma de garantir um bom estado de discussão coletiva e de circulação das idéias no seu interior. Essas posições não puderam evitar a aparição, inevitável e positiva em si, de orientações e tendências diferentes. Isso alimentaria, posteriormente, uma incipiente fissura.

Essa fissura não ocorria entre duas tendências, e sim entre dois estilos de trabalho: a primeira, popular, mais democrática, com o cuidado de reforçar seus vínculos com as massas. A outra, mais vanguardista, mais jovem também e de origem universitária, centralizadora ao extremo, tendia a dar prioridade às operações de comando e às concepções militares, e subestimava o trabalho político de organização nas frentes de massas e em seu próprio seio. Não se tratava, entretanto, de grupos claramente delimitados, nem de frações constituídas. Enquanto a velha direção esteve nos postos de comando, a primeira orientação triunfou sempre, sem discussões, pois a figura de Sendic como líder inato colocava fora de discussões - de forma natural - o exercício do poder. Como Max Weber diria, a submissão natural ante uma verdadeira autoridade "carismática".

Outra situação que deve ser considerada é a de que, nessa época, quase toda a direção histórica (os velhos dirigentes) se encontrava encarcerada no presídio de Punta Carretas. Isso fez com que fosse assumida a tendência militarista, conhecida pelo nome de "samurai". A falta de preparação e de experiência, o desconhecimento do funcionamento da organização e uma marcada incapacidade de análise política tomaram conta então do MLN. ${ }^{21}$ Sua homogeneidade interna era recente e fez com que surgisse, nesse momento, a "microfração", facilitada pela ausência de uma direção firme e prestigiada.

21 Parafraseando Debray: "A realidade parece confirmar pela negativa a relação estabelecida entre a flexibilidade da linha política e a solidez do instrumento militar - que não era tão sólido como parecia, por falta de uma verdadeira consolidação ideológica” (DEBRAY, Régis. Las Pruebas del Fuego: la crítica de las armas II. México: Siglo XXI, 1974, p. 125). 
Nesse contexto, a tarefa do momento era manter na ativa a organização - e os novos responsáveis a cumpriram a contento. Procurando, antes de tudo, a eficiência militar, realizaram uma impressionante série de operações, cujo impacto bastou para desmentir, na opinião pública, a idéia - incansavelmente propagada pela imprensa oficial - de que depois dos episódios que levaram à detenção dos dirigentes históricos, o MLN estava desmantelado. As lideranças históricas, por sua vez, não eram informadas pela nova direção, tanto que após a fuga do presídio de Punta Carretas, conhecida com o nome de El Abuso, em setembro de 1972, os dirigentes evadidos não reconheceram a organização que eles criaram. Como conseqüência dessa situação, os dirigentes históricos negaram-se a assumir novamente a direção do Comitê Executivo.

"O militarismo gera perdas das qualidades militares e da atitude para sustentar um encontro frontal com o inimigo, tanto mais pernicioso, porque tampouco se revela senão no último momento, em período de crise. Uma militarização excessiva produz um instrumento militar embotado e debilitado". ${ }^{22}$ Dessa forma Debray definiu a situação dos tupamaros em 1972. Certamente, a organização tinha mudado de forma significativa: existia um centralismo insuficientemente democrático, no qual as bases já não participavam na tomada de decisões e onde os órgãos dirigentes deixavam de se submeter ao controle do conjunto dos militantes; surgiu um autoritarismo vertical, violentando as normas e os estatutos da organização. Essas diferenças levaram a uma série de discussões entre as tendências enfrentadas, o que contribuiu para aprofundar a brecha entre ambas.

Em março de 1972, as críticas que se faziam ao Comitê Executivo eram as de haver dirigido a organização numa linha "esquerdista", como forma de representar o desvio ideológico em favor do militarismo. A esse qualificativo se acrescentavam algumas características "direitistas", uma sorte de combinações de contrários presentes nos "esquerdismos". Aquele extremo desvio esquerdista (colocar-se tão à frente das massas que se deixa de lado a realidade das mesmas) era a tradução política de um desvio ideológico de direita: as tendências nacionalistas haviam deslocado no interior do movimento as posições do marxismo-leninismo. Por isso o MLN caracterizou, na sua autocrítica, aquela etapa como "pequeno-burguesa".

22 DEBRAY, Régis. Las Pruebas del Fuego: la crítica de las armas II. Mexico: Siglo XXI. 1974, p. 164. 
Em 14 de abril de 1972, produziu-se uma seqüência de ações violentas por parte do MLN, através de múltiplos ataques contra integrantes de um grupo paramilitar ligado aos órgãos da repressão. As Forças Armadas responderam, no mesmo dia, com uma série de procedimentos que abalaram as estruturas do MLN. A partir desse momento, a organização pareceu perder capacidade de resposta e, num prazo de cinco meses, foi praticamente desmantelada. Essa derrota em tão breve lapso de tempo de uma organização que parecia estar, em abril de 1972, na plenitude de seu poderio causou uma explicável surpresa. Essa força era somente aparente. No início de 1972, o MLN atravessou a maior crise interna de sua história. Como afirmou Bonino, a crise foi resultante do confronto entre duas direções "paralelas": a direção "histórica" havia formado o MLN, enquanto a "nova" direção havia sido formada pelo MLN. ${ }^{23}$

\section{Considerações finais}

Pode-se observar três diferenciadas fases ou períodos na trajetória do MLN, desde sua incipiente formação em 1962 até sua derrota em 1973. A primeira, caracterizada pelo Coordinador, onde as discussões iniciais do que seria posteriormente uma organização armada tiveram as contribuições de variados setores da esquerda combativa. Esse período foi de tentativas de unificação de esforços que apontaram para a construção de uma hegemonia para a via armada no país, mesmo que com sérias carências teóricas e estratégicas. A prematura divisão dos quadros e setores nela intervenientes fracionou as possibilidades de uma "identidade" para a "revolução uruguaia" e, principalmente, para a esquerda combativa.

A segunda fase, iniciada em 1966 com a dissolução do Coordinador e com a constituição do MLN, imprimiu à nascente organização um período de construção identitária e política muito complexa que, com marcadas influências externas (como o caso de Debray), foi desenhando um perfil organizacional próprio, com base no marxismo-leninismo, e uma particular concepção da "revolução nacional" a partir do resgate da história e de tradições nacionais. Por outra parte, nesse período se iniciou um processo de consolidação de suas lideranças, fundamentalmente na figura de Raul Sendic, que gravou a fogo um estilo de militância e de transparência ética, política e ideológica.

23 BONINO, Costa Luis. Crisis de los Partidos Tradicionales y Movimiento Revolucionario en el Uruguay. Montevideo: Banda Oriental, 1988, p. 78. 
A terceira fase, iniciada em 1971, foi caracterizada por dois elementos de peso: o primeiro, a detenção por parte do Estado dos principais dirigentes da organização, deixando acéfala a direção executiva do movimento, que teve de substituir seus quadros dirigentes por quadros intermédios ainda em processo de formação; e o segundo, pela influência que esses quadros intermédios possuíam. Dessa forma, a fase ou período "militarista" do MLN mudou o perfil identitário que os dirigentes históricos vinham construindo desde a sua constituição, e possibilitou, a partir dessa nova direção ou "microfração", dar um outro rumo, tanto político como estratégico, na organização.

Criada com uma dupla função político-militar, a organização em si mesma se especializou como aparelho militar, deixando a função política nas mãos do Comitê Executivo, que avaliava, pensava e agia por ela. No período de 1972, esse aparelho militar foi adaptando os indivíduos a suas próprias necessidades estruturais; assim, acabou formando soldados no lugar de políticos. As ações de 14 de abril de 1972 e seus resultados podem ser explicados a partir dessa concepção "militarista" da "nova" direção. Segundo as críticas realizadas por Cores ${ }^{24}$, apesar dos erros - claramente explicitados na sua própria documentação -, parece que seu acionar foi visto, pelo menos durante os primeiros anos, com simpatia por setores decepcionados com a situação de crescente deterioração econômica e social e com a falta de respostas por parte do sistema político. Sua emergência alentou esperanças, avivou emoções e revelou faces da realidade do país até esse momento desconhecidas.

Em resumo, não é possível identificar uma "identidade" $t u$ pamara no interior da organização visto que, nesses períodos ou fases, o movimento passou por mutações ideológicas que imprimiram particularidades irreproduzíveis entre os diversos momentos. Como elemento identitário comum a esses períodos, pode-se assinalar uma tendência ao resgate da história nacional, fundamentalmente a tradição artiguista, conjuntamente com a influência de setores libertários presentes nas primeiras organizações populares no Uruguai de inícios do século XX. No que se refere à construção de uma identidade institucional em tupamaros, deve-se marcar o fato de que qualquer explicação possível não poderá deixar de lado os conflitos pelo poder interno travados, no terceiro período, no seio da organização.

Recebido em 5 de setembro de 2007.

24 CORES, Hugo. El 68 Uruguayo. Montevideo: Banda Oriental, 1997, p. 55. 